\title{
La muqueuse de l'intestin grêle : évolution de la composition en lipides cellulaires au cours de la différenciation entérocytaire et de la maturation postnatale
}

\author{
JM Alessandri *, TS Arfi, C Thieulin \\ IINRA-CRJ, laboratoire de nutrition et sécurité alimentaire, Jouy-en-Josas, 78352 Cédex, France
}

(Reçu le 29 décembre 1989; accepté le 18 juillet 1990)

\begin{abstract}
Résumé - Les données concernant les modifications quantitatives et qualitatives des principaux composants lipidiques cellulaires liées aux processus de différenciation et de maturation de la muqueuse intestinale sont passées en revue. Les évolutions des 3 principales classes de lipides membranaires de l'entérocyte, soit les phospholipides, le cholestérol et les glycolipides, sont examinées. La teneur en phospholipides cellulaires augmente depuis la base des cryptes jusqu'au sommet des villosités, reflétant ainsi la croissance des organites cellulaires et des membranes plasmiques au cours de la différenciation. La maturation postnatale de la muqueuse s'accompagne, pour sa part, d'une redistribution des différentes classes de phospholipides de la bordure en brosse intestinale. L'incidence de la nature des acides gras alimentaires sur l'évolution de la composition en acides gras des phospholipides intestinaux est discutée.
\end{abstract}

La biosynthèse endogène du cholestérol s'effectue principalement dans la partie basse des villosités, tandis que l'absorption du cholestérol luminal et son estérification dans les lipoproténes ont lieu dans les cellules matures de la partie supérieure. La teneur en cholestérol membranaire augmente dans les cellules matures par rapport aux cellules indifférenciées et dans l'intestin distal par rapport à l'intestin proximal. L'augmentation de la teneur en cholestérol est souvent en corrélation avec la diminution de la fluidité membranaire. Les modifications physico-chimiques des membranes cellulaires intestinales ont un rôle à jouer dans la régulation des fonctions digestives et absorptives de la muqueuse.

Les glycosphingolipides sont essentiellement présents dans les membranes de bordure en brosse, dont ils représentent $20-30 \%$ en poids des lipides. Ils contribuent à augmenter la stabilité de cette membrane et confèrent aux entérocytes une partie de leurs caractéristiques de surface. Celles-ci évoluent considérablement au cours de la différenciation et de la maturation de l'intestin. Les modifications structurales des différentes espèces moléculaires concernent aussi bien la partie glycosylée (externe) que la partie lipidique (membranaire) des glycolipides. La substitution de l'activité de la galactosyltransférase par la sialyltransférase au cours de la différenciation peut rendre compte de l'augmentation le long de la villosité de la teneur en hématosides chez le rat. Les processus de différentiation-maturation s'accompagnent d'une augmentation de l'hydroxylation des acides gras des glycolipides.

L'ensemble des modifications décrites participe au développement des fonctions de barrière et de perméabilité sélective de la muqueuse intestinale mature.

entérocyte / différenciation / intestin grêle / maturation / lipide

Correspondence and reprints 
Summary - Compositional changes of lipids in relation to cell differentiation and postnatal maturation in the small intestine. Alterations in lipids linked to intestinal maturation and enterocyte differentiation were reviewed. The 3 main lipid components of cell membranes, ie cholesterol, phospholipids and glycolipids, were examined.

Cell phospholipid content increases from the crypts to the mid-villus, which accounts for membrane development and organelle growth in differentiating cells. Changes in the proportion of phospholipid polar head groups occur in brush border membrane during postnatal maturation of the small intestine. The possibility that phospholipid fatty acid composition in differentiating cells might be altered by dietary lipids is discussed. Cholesterol biosynthesis mainly occurs in crypt and lower villus cells whereas its absorption from luminal content and esterification into lipoproteins occur in upper villus mature cells. Cholesterol cell content increases in mature cells in comparison to immature cells on the one hand, and in the distal by comparison with proximal parts of the intestine on the other. Increasing cholesterol content is generally correlated with decreasing membrane fluidity, which in turn could modulate functional properties of the mucosa.

Glycosphingolipids are mainly found in the brush border membrane, which contains $20-30 \%$ glycolipids by weight of total lipids. These components tend to reinforce the membrane stability and significantly contribute to the surface properties of epithelial cells. The latter undergo noticeable changes during cell differentiation and postnatal maturation. Significant changes in both the glycosidic and lipophilic parts of glycosphingolipid molecules occur in differentiating cells and are of possible importance in the process of mucosal maturation. It is possible that the addition of a terminal sialic acid (sialyltransferase activity) instead of a terminal galactose (galactosyltransferase) to an endogenous acceptor (lactosylceramide) could constitute an important event in the differentiation process, and may account for the increasing content of hematosides along the intestinal villus of rat. Alterations in lipid counterpart mainly consist of hydroxylation of fatty acids in hematosides during postnatal maturation or in glucosylceramides during cell differentiation.

Collectively these intestinal lipid changes may contribute in part to the development of mucosal barrier, selective permeability and functional properties of the mature intestinal mucosa.

enterocyte / differentiation / small intestine / maturation / lipid

\section{INTRODUCTION}

Les cellules épithéliales de l'intestin grêle ont une durée de vie particulièrement courte : de $2-3$ j chez les rongeurs, de 5-6 j chez l'homme. Au cours de cette période les cellules intestinales évoluent d'un stade prolifératif localisé à la base des cryptes, à une phase de différenciation accélérée qui correspond à la mise en place des caractéristiques structurales et fonctionnelles de l'entérocyte mature (revue de Klein et McKenzie, 1983). Les processus de différenciation et de maturation qui accompagnent la migration de l'entérocyte le long de l'axe crypto-villositaire se traduisent par un ensemble de modifications structurales (Van Dongen et al, 1976; Madara et al, 1980; Leblond, 1981) conduisant à l'allongement des cellules, à l'augmentation du nombre d'organites cellulaires (mitochondries, appareil de Golgi), au développement des jonctions serrées entre cellules adjacentes, à la croissance des structures microvillositaires de la membrane apicale (bordure en brosse) et à l'épaississement de la couverture glycoprotéique ancrée dans cette membrane, le glycocalyx.

Les membranes de bordure en brosse des cellules qui émergent de l'embouchure des cryptes et qui s'engagent sur l'axe villositaire incorporent les hydrolases et les systèmes de transport de nutriments nécessaires aux fonctions de digestion et 
d'absorption de la muqueuse. Dans le même temps, certaines caractéristiques de surface de la cellule reconnues par de nombreuses molécules telles que des hormones, des anticorps, des lectines végétales, des adhésines ou des toxines bactériennes se mettent en place. Le bouleversement des structures glycosylées constitue l'une des caractéristiques essentielles de la différenciation entérocytaire, dont la description a fait l'objet de revues très détaillées (Mooseker et Howe, 1982; Noren et al, 1986; Weiser et al, 1986).

Depuis quelques années, un nouveau champ d'investigation s'est développé autour de l'évolution de la composition lipidique des membranes. Les caractéristiques physico-chimiques de la matrice lipidique régulent en effet de nombreuses propriétés fonctionnelles membranaires, parmi lesquelles on peut citer la perméabilité, de nombreuses activités enzymatiques et l'accessibilité de quelques récepteurs (voir les revues de Sandermann, 1978; Brenner, 1984; Stubbs et Smith, 1984).

Il est bien établi que la qualité de la matrice lipidique des membranes biologiques est très étroitement liée à la nature des acides gras (revues de Clandinin et al, 1985; Holmes et Kummerow, 1985; McMurchie, 1988). En revanche, l'incidence de la composition lipidique de l'aliment sur le déroulement in vivo des processus de différenciation d'une cellule à renouvellement rapide, telle que l'entérocyte, n'a fait l'objet que d'un nombre restreint d'études. Cette mise au point a pour objectif de présenter un bilan des principales données relatives aux modifications du métabolisme lipidique qui accompagnent la maturation et le renouvellement de la muqueuse de l'intestin grêle. Dans la mesure du possible, les critères retenus permettront de comparer les modifications de la composition lipidique entre cellules indifférenciées et cellules matures, entre extrémité proximale et extrémité distale de l'intestin, entre muqueuse du nouveau-né et muqueuse de l'adulte.

\section{Biosynthèse, structure et composition des phospholipides de l'entérocyte}

\section{Évolution de la biosynthèse au cours de la différenciation cellulaire}

Les phospholipides représentent, avec les glycolipides et le cholestérol, les principaux constituants lipidiques de la membrane de bordure en brosse (tableau 1). D'Harlingue et ses collaborateurs (1986) ont analysé l'évolution du contenu cellulaire en phospholipides (PL) totaux dans les cellules intestinales de jéjunum de rats, extraites selon la méthode de Weiser (1973) par fractions successives depuis l'extrémité des villosités jusqu'à la base des cryptes. En rapportant les résultats au contenu en ADN cellulaire, ces auteurs ont mis en évidence une augmentation régulière du taux de phospholipides accompagnant la croissance et la migration de l'entérocyte le long de la villosité : chez le rat âgé de 2 à 5 semaines, le contenu en phospholipides augmente de $1 \mathrm{mg}$ PL/mg ADN dans les cellules de la base des cryptes à 3-4 mg PL/mg ADN dans les cellules provenant du sommet des villosités. L'accumulation progressive de phospholi-

Tableau I. Composition lipidique globale (en $\mathrm{g}$ pour $100 \mathrm{~g}$ de lipides totaux) de la bordure en brosse intestinale de rat adulte, d'après Brasitus et Schachter (1980).

\begin{tabular}{lr}
\hline Phospholipides totaux & 34,1 \\
Glycolipides & 29,6 \\
Cholestérol & 14,3 \\
Acides gras libres & 14,2 \\
Cholestérol estérifié & 4,8 \\
Triglycérides & 1,6
\end{tabular}


pides dans les entérocytes rend compte en partie du développement des organites cellulaires, et notamment de la croissance de la bordure en brosse qui concentre environ $14 \%$ des phospholipides cellulaires totaux (d'Harlingue et al, 1986).

II existe très peu d'informations concernant les interrelations éventuelles entre la nature de la partie polaire des phospholipides membranaires et les processus de différenciation de l'entérocyte. Jusqu'à présent, une seule étude effectuée chez le rat suggère qu'une diminution de la fluidité de la bordure en brosse se produit au cours de la différenciation, mais cette rigidification ne semble liée, ni à une modification de la quantité de phospholipides incorporés dans la membrane, ni à une modification de la distribution des différentes classes de phospholipides (Brasitus et Dudeja, 1985). En considérant l'ensemble des phospholipides contenus dans la cellule, nous avons estimé que le rapport global entre les 2 classes majoritaires (phosphatidylcholine et phosphatidyléthanolamine) était compris entre 1,2 et 1,4 chez le rat sevré, ceci indépendamment de la position de l'entérocyte le long de la villosité (Alessandri et Arfi, résultats non publiés).

Des mesures de l'activité de 11 enzymes impliquées dans la biosynthèse des phospholipides ont été réalisées in vitro sur des cellules intestinales de rat (O'Doherty, 1978). Les résultats obtenus montrent que les cellules indifférenciées des cryptes possèdent l'équipement enzymatique nécessaire à la biosynthèse des phospholipides et suggèrent que le niveau d'activité de certaines de ces enzymes évolue avec la migration cellulaire le long de la villosité, en particulier celui des lysophospholipide acyltransférases, dont les activités spécifiques augmentent de façon significative depuis la base des cryptes jusqu'au sommet des villosités (fig 1). La synthèse du phosphatidylinositol et de la sphingomyéline (respectivement, activités spécifiques de la CTP-diacylglycérol: inositol phosphatidyltransférase et de la CDP. choline : $\mathrm{N}$-acylsphingosine cholinephosphotransférase) est de 2-3 fois plus élevée dans les cellules matures que dans les cellules de la base des cryptes. L'activité de l'enzyme responsable de la biosynthèse de la phosphatidylsérine par remplacement de l'éthanolamine (phosphatidyléthanolamine-L-sérine phosphatidyltransférase) augmente de 4-5 fois au cours de la migration cellulaire, tandis que la rétroconversion de la phosphatidylsérine en phosphatidyléthanolamine par décarboxylation ne semble pas dépendre du niveau de différenciation. De même, la voie de biosynthèse de la phosphatidylcholine et de la phosphatidyléthanolamine utilisant les esters de la cytidine diphosphate semble indépendante de la position des cellules le long de l'axe crypto-villositaire. La voie de transméthylation de la phosphatidyléthanolamine en phosphatidylcholine,

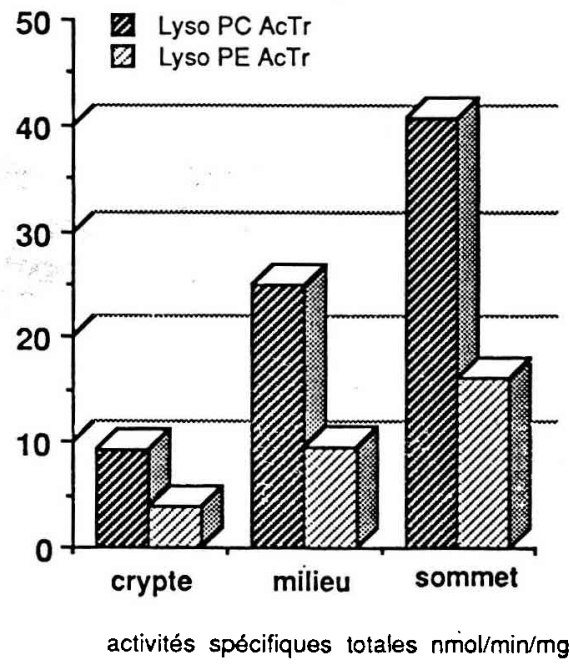

Fig 1. Niveaux comparés des activités lysophosphatidylcholine acyltransférase (Lyso PC AcTr) et lysophosphatidyléthanolamine acyltransférase (Lyso PE AcTr) dans les cellules des cryptes, du milieu et du sommet des villosités intestinales de rat. D'après O'Doherty (1978). 

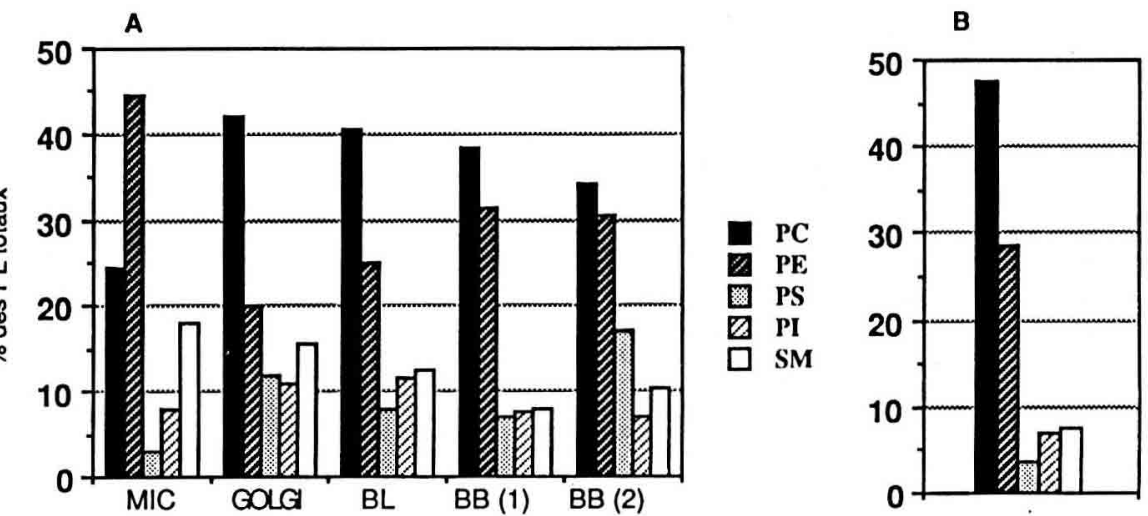

Fig 2. A. Distribution des différentes classes de phospholipides dans les microsomes (MIC), les membranes golgiennes (GOLGI), les membranes basolatérales (BL) et la bordure en brosse (BB) d'entérocytes de rat. Les données de la littérature sont comparées lorsqu'elles correspondent à l'intestin proximal de rats adultes nourris avec des aliments d'élevage standards. Les valeurs proviennent des références suivantes : MIC: Garg et al (1988); GOLGI : Brasitus et al (1988a); BL: Chapelle et GillesBaillien (1983); BB1: Chu et Walker (1988); BB2: Schwarz et al (1985). Classes de phospholipides: PC: phosphatidylcholine + lysophosphatidylcholine; PE : phosphatidyléthanolamine + lysophosphatidyléthanolamine; PS : phosphatidylsérine; PI : phosphatidylinositol; SM: sphingomyéline. Ces 5 classes représentaient respectivement $97,7 \%, 99,8 \%, 97,4 \%, 92 \%$ et $98,9 \%$ des phospholipides totaux contenus dans MIC, GOLGI, BL, BB1 et BB2. B. Distribution des 5 classes de phospholipides dans les bordures en brosse de rats nouveau-nés. D'après Chu et Walker (1988).

récemment mise en évidence dans la bordure en brosse intestinale de rat (Dudeja et Brasitus, 1987), n'a pas été examinée dans cette étude. Ces 2 dernières classes sont les principaux constituants des phospholipides membranaires de l'entérocyte (fig 2). Chez le rat, la phosphatidylcholine et la phosphatidyléthanolamine représentent environ $70 \%$ des phospholipides totaux de la bordure en brosse intestinale.

\section{Évolution de la composition en acides gras des phospholipides au cours de la différenciation: incidence de l'alimentation}

L'augmentation de l'activité d'estérification des acides gras effectuée par les lysophospholipide acyltransférases concorde, d'une part, avec le développement accélé- ré des structures membranaires au cours de la différenciation et, d'autre part, avec le turn-over important des membranes apicales, endommagées par suite de leur exposition au contenu intestinal et renouvelées de façon permanente. Mais l'intensification de l'ensemble des activités acyltransférases observée dans les cellules matures par rapport aux cellules des cryptes peut rendre compte également de l'augmentation de la biosynthèse des phospholipides, triglycérides et esters de cholestérol incorporés dans les chylomicrons ou dans les VLDL, et sécrétés dans la lymphe (Iglesias et al, 1989). Vingt à trente pour cent des phosphatidylcholines véhiculées par les chylomicrons lymphatiques contiennent des acides gras exogènes, réestérifiés dans l'entérocyte après lipolyse des triglycérides alimentaires (revue de Boucrot, 1983). On peut donc 
distinguer 2 pools de phospholipides dans l'entérocyte : I'un impliqué dans la mise en place et la maintenance des structures membranaires, l'autre dans l'élaboration de la fraction phospholipidique des lipoprotéines sécrétées par la muqueuse intestinale (O'Doherty et al, 1977). Il est vraisemblable que chacun de ces pools évolue de façon spécifique au cours des processus de différenciation et de maturation entérocytaires.

La composition en acides gras des triglycérides alimentaires peut exercer une influence considérable sur celle des phospholipides cellulaires extraits aux différents stades de maturation le long de la villosité. Des résultats récents obtenus dans notre laboratoire montrent que, lorsque des rats sont nourris avec un aliment enrichi en acide linoléique par l'apport d'huile de maïs, les teneurs en acides linoléique et arachidonique des phospholipides cellulaires totaux augmentent parallèlement à la progression des cellules dans la partie basse des villosités (Alessandri et al, 1990). Dans ce cas, l'acide arachidonique représente de $12-15 \%$ des acides gras totaux contenus dans les phospholipides des cellules des cryptes. Cette teneur s'élève à $20-25 \%$ dans les cellules matures du milieu des villosités (fig 3A). La teneur en acide linoléique est de 1,5-2 fois moins élevée que la teneur en acide arachidonique. Si les rats reçoivent dès le sevrage une alimentation déficiente en acides gras polyinsaturés, les teneurs cellulaires en acides linoléique et arachidonique deviennent de $2-3$ fois plus faibles que celles du groupe "huile de maïs" (fig 3B). L'acide arachidonique ne représente plus que de $6-12 \%$ des acides gras totaux, la diminution de cet acide gras étant compensée par l'apparition du 20:3n-9 en proportion équivalente (fig 3B). Ce type de compensation ne permet pas aux rats carencés de «récupérer» le même niveau d'insaturation des PL cellu- laires que celui des animaux témoins (Alessandri et al, 1990).

II a été montré par ailleurs que ce type de carence en acides gras essentiels peut entraîner d'importantes modifications d'ordre morphologique, structural et fonctionnel de la muqueuse, chez le rat ou la souris (Snipes, 1967, 1968). Chez les animaux carencés, les cellules émergent des cryptes dans un état de différenciation incomplète. Elles présentent des anomalies de formation des différents organites cellu-
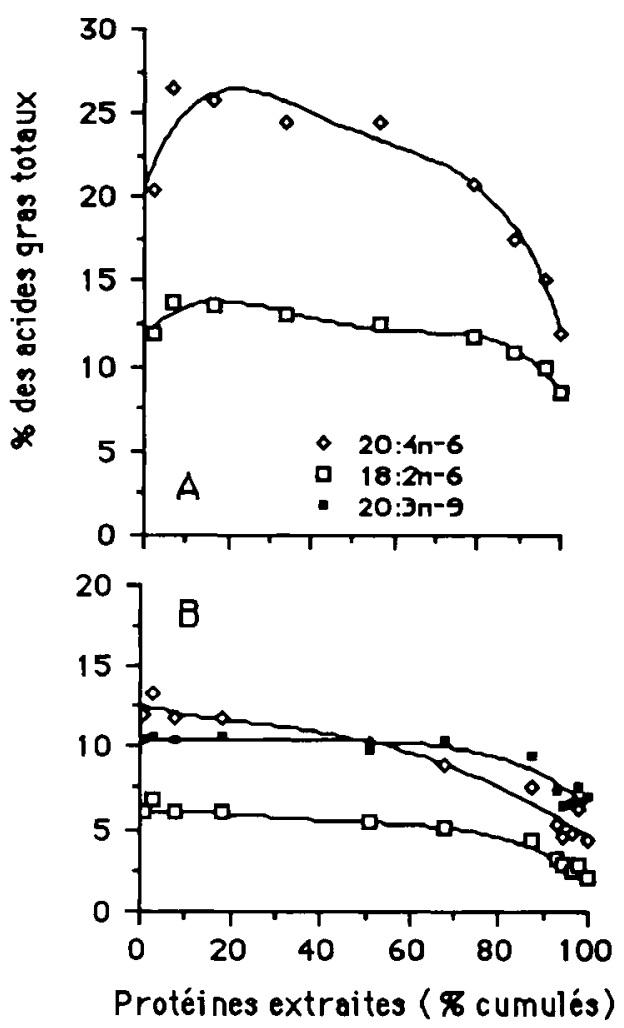

\section{Sommets} Cryptes

Fig 3. Evolution de la composition en acides gras des PL totaux de l'entérocyte de rat le long de l'axe crypto-villositaire. Les rats sont nourris dès le sevrage et pendant 3 semaines avec un aliment contenant soit de l'huile de maïs (A), soit de l'huile de coprah hydrogéné $(B)$. 
laires, notamment de l'appareil de Golgi qui semble dilaté, des mitochondries dont les crêtes sont peu nombreuses et peu développées et des microvillosités qui sont raccourcies et qui apparaissent clairsemées. L'absorption intestinale des lipides est retardée chez les animaux carencés et elle est restreinte à une très faible surface de la partie supérieure de la villosité (Snipes, 1968). Les vitesses de division, de migration et d'extrusion cellulaires sont augmentées par la carence en acides gras essentiels, l'ensemble de ces processus conduisant à une modification de l'architecture villositaire (Snipes, 1967). En outre, la carence peut altérer les mécanismes d'adaptation qui répondent normalement à une résection intestinale partielle (Hart et al, 1988). Une perturbation de la biosynthèse de certaines prostaglandines impliquées dans les processus régénératifs pourrait être à l'origine de l'effet induit par la carence alimentaire en acides gras polyinsaturés, précurseurs indispensables à la synthèse des prostanoïdes.

La composition globale en acides gras des phospholipides est donc susceptible d'évoluer lors de la migration cellulaire le long de la villosité. Cette redistribution dépend de la disponibilité des acides gras polyinsaturés, c'est-à-dire, pour une bonne part, de la qualité de l'apport lipidique alimentaire. Elle dépend également de l'affinité des acyltransférases pour les différentes molécules d'acides gras. $\grave{A}$ cet égard, il peut être remarqué que l'incorporation in vitro du 18:2n-6 dans les membranes des microsomes intestinaux est plus importante que celle du 16:0, aussi bien au niveau du jejunum qu'au niveau de liléon, suggérant une affinité plus élevée des acyltransférases entérocytaires pour le précurseur de la famille des n-6 (Garg et al, 1988). II existe cependant des différences régionales, puisque les vitesses d'incorporation de ces 2 acides gras dans les microsomes sont plus élevées au ni- veau du jéjunum qu'au niveau de l'iléon. L'incorporation du 20:4n-6 n'a pas été examinée dans cette étude.

Il reste à déterminer si le remodelage de la composition en acides gras des phospholipides membranaires obéit à des règles spécifiques de chacun des différents compartiments membranaires de l'entérocyte (qui, d'ailleurs, n'ont pas les mêmes vitesses de renouvellement). Cela semble être le cas, puisqu'une diminution de la teneur en acide oléique (18:1n-9) dans les phospholipides de la bordure en brosse des cellules des villosités par rapport à celles des cryptes a été observée chez le rat (teneurs respectivement égales à 11,2 et $17,5 \%$ ), tandis que, dans cette unique expérience, les teneurs en acides gras de la série $n-6$ le long de la villosité restaient inchangées (Brasitus et Dudeja, 1985).

\section{Évolution de la structure des phospholipides au cours de la maturation postnatale de l'intestin}

Une des propriétés particulières de l'intestin néonatal réside dans sa capacité d'absorber des macromolécules alimentaires et des immunoglobulines par endocytose (revue de Kédinger et al, 1986b). Plusieurs chercheurs ont suggéré que l'ensemble des modifications postnatale ou après sevrage, affectant la composition lipidique des membranes plasmiques, pouvait contribuer au développement des fonctions de barrière et de perméabilité sélective caractéristiques de la muqueuse intestinale mature (Chu et Walker, 1988; Schwarz et al, 1984, 1985, 1989).

Les glucocorticoïdes naturels ou de synthèse, tels que la cortisone ou la dexaméthasone, sont connus pour stimuler la maturation fonctionnelle de la muqueuse et favoriser la mise en place des propriétés de barrière intestinale. La dexaméthasone 
est capable, en agissant au niveau transcriptionnel, d'induire l'apparition des activités saccharase et maltase (Kédinger et al, 1986b). La mise en évidence de la modulation des propriétés biophysiques des membranes microvilleuses intestinales par ces hormones a fait l'objet de quelques investigations. Une attention particulière a été portée sur l'effet de l'injection de glucocorticoïdes aux rats nouveau-nés ou aux rattes en gestation. II a ainsi été montré que l'administration de ces agents provoque la diminution de la fluidité des membranes microvilleuses du fotus ou du nouveau-né et induit l'apparition précoce de certaines caractéristiques de surface de l'entérocyte (Pang et al, 1985; Neu et al, 1986). Malheureusement, l'effet des glucocorticoïdes sur la composition lipidique des membranes n'a pas été déterminé dans ces expériences. Des résultats apparemment contradictoires ont été obtenus par Brasitus et al (1987). Selon ces auteurs, l'injection de dexaméthasone a provoqué, chez le rat adulte, l'augmentation de la fluidité de la membrane de bordure en brosse en corrélation avec une modification de la composition lipidique. Le traitement $a$ induit l'augmentation de la teneur relative en phosphatidylcholine (de $3,8 \%$ en poids des lipides) et la diminution de l'index de saturation $(0,32$ contre 0,40$)$ principalement due à l'enrichissement de cette classe de phospholipides en 18:2n-6 et en $20: 4 n-6$. Ces résultats valident donc l'hypothèse d'un effet des glucocorticoïdes sur les caractéristiques physico-chimiques des membranes apicales de l'intestin. Les différences enregistrées entre les types d'expérimentation suggèrent que le stade de développement d'une part, les modifications alimentaires liées au sevrage d'autre part, introduisent une variable importante dans la détermination des modifications structurales induites par ces hormones.
II ressort d'une étude utilisant la spectroscopie électronique que la membrane de bordure en brosse du nouveau-né peut être considérée comme étant moins ordonnée que celle de l'adulte (Pang et al, 1983). Cette différence d'organisation structurale pourrait (partiellement) rendre compte de la plus grande perméabilité aux macromolécules observée pendant la période néonatale. On peut remarquer par analogie que, chez la souris adulte, la vitesse d'endocytose est 2 fois plus élevée dans les cellules intestinales indifférenciées que dans les cellules matures (Heyman et al, 1989). La captation des macromolécules par endocytose implique l'adsorption des substances sur la surface de la membrane apicale et l'invagination de celle-ci (Walker et al, 1972). Ces processus pourraient être favorisés par l'environnement membranaire plus désorganisé des sites de la bordure en brosse du nouveau-né impliqués dans l'endocytose (Pang et al, 1983).

On peut donc concevoir que l'évolution de la composition en lipides des membranes microvilleuses représente un des éléments du contrôle du transport macromoléculaire pendant la période néonatale. Les analyses comparées de la répartition des différentes classes de phospholipides dans la bordure en brosse chez le nouveau-né et chez ladulte ont montré que la maturation postnatale de l'intestin de rat s'accompagne d'une redistribution des groupements polaires des molécules de phospholipides (Chu et Walker, 1988), conduisant notamment à une modification du rapport phosphatidylcholine/phosphatidyléthanolamine. Celui-ci est proche de 2 dans les bordures en brosse de rat nouveau-né, tandis que les proportions respectives de ces 2 classes tendent à s'équilibrer chez l'adulte (fig 2). L'activité spécifique de la 1,2 diglycérol-CDP choline phosphocholine transférase, impliquée 
dans la biosynthèse de la phosphatidylcholine, est 4 fois plus élevée dans les microsomes intestinaux du fotus comparativement au rat adulte (Engelhardt et al, 1989).

Une autre étude récente, effectuée chez le lapin avant et après sevrage, montre que les membranes basolatérales sont également soumises à des modifications de composition phospholipidique liées à la maturation intestinale. Celles-ci se traduisent, dans les membranes basolatérales des lapins sevrés, par une élévation des teneurs relatives en phosphatidylcholine et sphingomyéline, le contenu total en phospholipides (environ $0,4 \mu \mathrm{mol} / \mathrm{mg}$ de protéines) restant inchangé (Schwarz et al, 1989). La sphingomyéline pourrait exercer un effet stabilisant sur la bicouche lipidique (Sandermann, 1978). On peut également émettre l'hypothèse que des changements dans la distribution des classes de phospholipides se traduisent par des modifications d'associations entre domaines protéiques insérés dans la bicouche et phospholipides membranaires.

D'une façon générale, toute modification notable de la composition en classes de phospholipides membranaires est susceptible d'induire une (ou plusieurs) réponse (s) fonctionnelle(s). À titre d'exemple, on peut rappeler l'hypothèse selon laquelle la stimulation de la biosynthèse de phosphatidylcholine enrichie en acides gras polyinsaturés, suivie de l'incorporation dans la membrane microvilleuse de la PC néosynthétisée, constituerait le mécanisme initial par lequel la 1,25-dihydroxyvitamine D3 stimule l'absorption intestinale du calcium in vivo (revue de Rasmussen et al, 1982). La modification structurale de la matrice lipidique induite par la 1,25-dihydroxyvitamine D3 se traduirait par une augmentation de la fluidité membranaire virtuellement responsable de l'augmentation de la vitesse d'absorption transmembranaire $\mathrm{du}$ calcium.
Plusieurs équipes de chercheurs, utilisant des sondes membranaires fluorescentes (telles que le DPH), ont démontré que la fluidité de la bordure en brosse intestinale de rat ou de lapin diminue au cours des processus de maturation postnatale qui précèdent ou accompagnent le sevrage (Schwarz et al, 1984, 1985; Pang et al, 1983, Brasitus et al, 1984; Meddings et Theisen, 1989). Le même phénomène a été mis en évidence dans les membranes basolatérales de lapin (Schwartz et al, 1989). Dans ces différentes expériences la diminution de la fluidité membranairo était en corrélation avec un ou plusiec s paramètres, tels que la diminution de l'index d'insaturation des acides gras, la modification de la distribution des classes de phospholipides, l'augmentation du rapport molaire cholestérol/phospholipides, ou encore, l'augmentation du rapport pondéral protéines/phospholipides. Plusieurs de ces facteurs sont souvent associés, mais il émerge de ces différentes études une relation commune entre l'augmentation du rapport molaire cholestérol/phospholipides et la diminution de la fluidité membranaire.

\section{Métabolisme du cholestérol dans l'entérocyte}

L'intestin est un site de synthèse endogène du cholestérol, dont l'importance varie selon les espèces. Chez le rat, les biosynthèses intestinale et hépatique représentent respectivement $25 \%$ et $50 \%$ de la cholestérogenèse corporelle. Chez d'autres espèces, telles que le lapin, le cobaye, le hamster et le singe-écureuil, l'intestin peut synthétiser autant, voire davantage, de cholestérol que le foie (Spady et Dietschy, 1983). II est bien établi que, dans l'entérocyte, les voies de biosynthèse et d'absorption du cholestérol évoluent avec la migration cellulaire le long de la 
villosité. Deux aspects de la physiologie cellulaire liés au métabolisme du cholestérol sont considérés dans ce chapitre : I'un concerne l'activité proliférative des cellules indifférenciées, l'autre découle du rôle particulier attribué au cholestérol dans la régulation de la fluidité des membranes biologiques.

\section{Róle du cholestérol dans la proliféra- tion et la différenciation cellulaires}

Le pool de cholestérol de l'entérocyte est régulé par une multitude de mécanismes qui établissent un équilibre entre les besoins en cholestérol de la cellule et de l'organisme, la synthèse endogène, le captage de lipoprotéines circulantes (LDL) et l'absorption du cholestérol luminal. L'importance relative de chacune de ces voies varie le long de l'intestin d'une part, et selon la position cellulaire le long de la villosité d'autre part.

Depuis les travaux de Srere et al (1948), qui ont observé que des tissus en croissance présentaient une intense activité cholestérogénique, de nombreuses études ont démontré qu'il existe, en général, une excellente corrélation entre les vitesses de réplication cellulaire et de synthèse du cholestérol (revue de Siperstein, 1984). Les résultats de nombreux travaux fondés sur l'utilisation d'inhibiteurs compétitifs de l'enzyme clé de la biosynthèse des stéroïdes, I'HMG-CoA réductase ( $\beta$ hydroxy, $\beta$-méthyl-glutaryl-CoA réductase), confirment que la prolifération et la croissance cellulaires dépendent étroitement de la disponibilité du cholestérol lui-même, mais aussi de celle d'autres métabolites (ubiquinone, dolichol, etc) issus du précurseur commun des isoprénoïdes, l'acide mévalonique (Kaneko et al, 1978; Brown et Goldstein, 1980; Quesney-Huneeus et al, 1983; Maltese, 1984). Indépendamment de son rôle de précurseur dans la cholestérogenèse, l'acide mévalonique pourrait exercer un effet direct sur l'initiation de la replication de l'ADN, comme cela a été montré dans le cas de cellules en culture (Quesney-Huneeus et al, 1979; Fairbanks et al, 1984; Siperstein, 1984).

Les cellules dont le besoin en cholestérol est le plus élevé sont donc les cellules en phase de prolifération ou d'extension des membranes plasmiques. Ces 2 phases caractérisent l'état des populations cellulaires situées respectivement dans la partie inférieure des cryptes et dans la partie inférieure des villosités, sites respectifs de synthèse du cholestérol et de captage des LDL dans l'intestin (Stange et Dietschy, 1983b). Environ $60 \%$ du captage intestinal des LDL s'effectue par une voie impliquant des récepteurs spécifiques (Stange et Dietschy, 1983b). La vitesse de biosynthèse du cholestérol dans les cellules prolifératives et dans les cellules en cours de différenciation est environ 2 fois plus élevée que dans les cellules de la partie supérieure des villosités, qui ne se divisent plus et dont la croissance est achevée (Dietschy et Siperstein, 1965; Stange et Dietschy, 1983a). Soixante à quatrevingt-cinq pour cent du cholestérol contenu dans les cellules des cryptes proviennent ainsi de la biosynthèse endogène (Stange et Dietschy, 1983b). En définitive, les cellules des cryptes assurent $30-40 \%$ de la capacité totale de l'intestin à synthétiser le cholestérol (Stange et Dietschy, 1983a). En revanche, les cellules matures de la partie supérieure des villosités, siège du flux entrant de cholestérol luminal, se caractérisent par une activité élevée d'estérification du cholestérol (activité acyl-CoA cholestérol acyltransférase). Le cholestérol estérifié est principalement destiné à la sécrétion sous forme lipoprotéique (Norum et al, 1983; Stange et al, 1983).

II existe enfin des différences régionales liées, semble-t-il, aux spécificités fonction- 
nelles des différentes parties de l'intestin. Chez de nombreuses espèces, dont l'homme, le singe et le rat, l'absorption du cholestérol luminal s'effectue principalement dans le jéjunum proximal. Inversement, la vitesse de synthèse du cholestérol endogène est globalement 3-4 fois plus élevée dans la région distale que dans la région proximale de l'intestin de rat (Dietschy et Siperstein, 1965; Stange et al, 1981; Stange et Dietschy, 1983a).

Stange et al (1988) ont proposé un modèle synthétique de compartimentation du cholestérol intra-entérocytaire dans lequel le pool de cholestérol non estérifié, métaboliquement actif, est alimenté principalement par les voies de synthèse endogène et de captage des LDL circulantes. En revanche, la plus grande partie du cholestérol exogène absorbé par l'entérocyte est estérifiée et incorporée dans les chylomicrons. Ce modèle attribue ainsi au cholestérol néosynthétisé un rôle structural principalement local, l'absorption du cholestérol exogène et sa sécrétion sous forme estérifiée par les cellules matures permettant de pourvoir à une grande part des besoins systémiques (Stange et Dietschy, 1985; Schneider et Stange, 1987). Le développement des structures membranaires implique donc l'incorporation de cholestérol non estérifié, prélevé à partir d'un pool endogène, dont la disponibilité apparaît clairement comme un facteur déterminant de la croissance cellulaire (fig 4).

\section{Rôle du cholestérol dans la physiologie et la fluidité des membranes de l'entéro- cyte}

La comparaison des valeurs du rapport molaire cholestérol/phospholipides entre les différents compartiments membranaires de l'entérocyte indique que la bordure en brosse intestinale est particulièrement riche en cholestérol (tableau I et

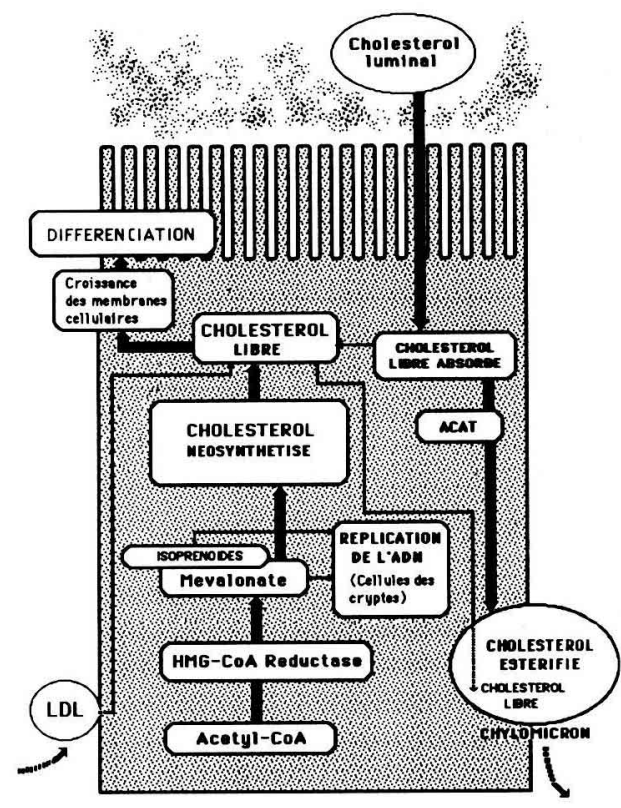

Fig 4. Métabolisme intestinal du cholestérol. Schéma adapté du modèle proposé par Stange et al (1988).

fig 5). La rigidité du noyau stérol confère à la molécule de cholestérol un rôle majeur dans la régulation des propriétés dynamiques des lipides membranaires (voir notamment les revues de Yeagle, 1985, 1989). Selon Brasitus et Dujeda (1985), l'augmentation du rapport cholestérol/ phospholipides au cours de la migration cellulaire représente l'un des principaux facteurs virtuellement responsables de la diminution de la fluidité des membranes microvilleuses des entérocytes matures (chol/PL $=0,99$ ) comparativement à celle des cellules des cryptes (chol/PL $=0,7$ ).

Brasitus et Schachter (1982) ont entrepris de moduler la biosynthèse du cholestérol par le biais de l'alimentation, afin d'établir une corrélation entre la modification de la cholestérogenèse intestinale et la variation de la fluidité des membranes 
microvilleuses. D'après ces auteurs, la biosynthèse intestinale du cholestérol diminue chez des rats nourris avec un aliment contenant du taurocholate de sodium (sel biliaire), et se trouve stimulée chez ceux qui reçoivent un aliment contenant de la cholestyramine (résine complexant les sels biliaires). Cette expérience montre que l'apport de cholestyramine a pour effet d'augmenter l'activité de I'HMG-CoA réductase mesurée in vitro, d'augmenter le contenu en cholestérol de la bordure en brosse (de $4 \mathrm{~g}$ pour $100 \mathrm{~g}$ de lipides totaux) et de diminuer la fluidité de cette membrane estimée par les paramètres d'anisotropie de fluorescence (DPH). Inversement, le taurocholate alimentaire induit simultanément la diminution de l'activité de biosynthèse du cholestérol (d'un facteur 1,6 par rapport au groupe précédent) et l'augmentation de la fluidité de la membrane microvilleuse. Les auteurs observent également une activation du transport de glucose sodium-dépendant dans les vésicules de bordure en brosse dont la fluidité était augmentée par l'apport de taurocholate.

Les conclusions de ces travaux, qui établissent des interrelations entre biosynthèse du cholestérol, fluidité membranaire et fonctions intestinales, peuvent être comparées aux données classiques décrivant les différences métaboliques et fonctionnelles des régions proximale et distale de l'intestin. En accord avec les différences décrites dans les études de régionalisation de la biosynthèse du cholestérol, plusieurs équipes ont rapporté que les membranes microvilleuses de liléon possèdent une teneur en cholestérol plus élevée et se caractérisent par une fluidité moindre que celle des membranes du jéjunum proximal (Schachter et Shinitzky, 1977; Brasitus et Schachter, 1982; Meddings, 1988). II semble cependant que l'intestin humain constitue une situation exactement inverse

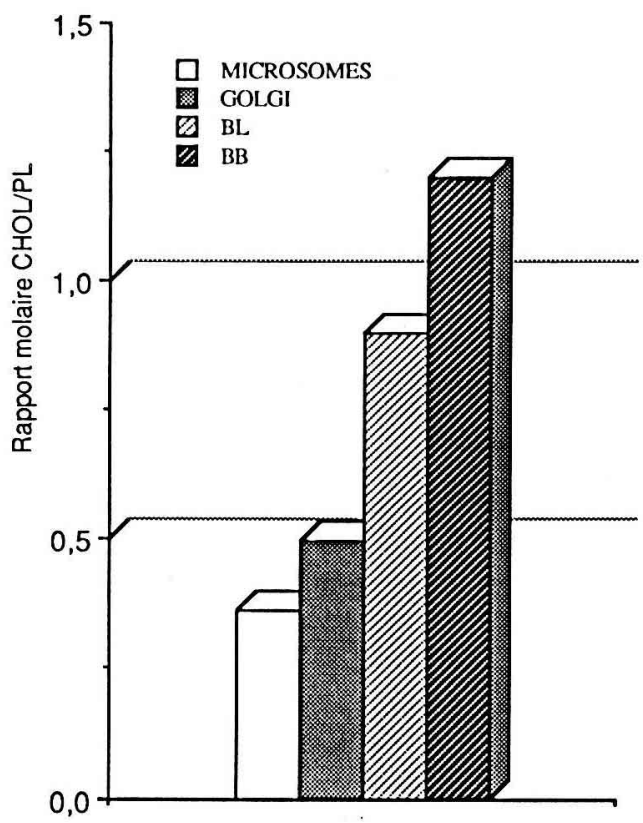

Fig 5. Valeurs du rapport molaire cholestérol/ phospholipides dans les différentes membranes d'entérocytes de rat adulte (intestin proximal). Les conditions et les références sont identiques à celles citées dans la légende de la fig 2.

: chez l'homme, il a été montré récemment que la fluidité de la membrane de bordure en brosse intestinale est plus élevée dans la région distale que dans la région proximale (Dudeja et al, 1989). Toutefois, cette différence de fluidité peut également être reliée à une différence de teneur en cholestérol membranaire, celle-ci étant plus élevée dans les membranes proximales (chol/PL $=0,7$ ) que dans les membranes distales (chol/PL $=0,5$ ).

Dans les études utilisant le modèle animal, les membranes microvilleuses proximales (plus «fluides") possèdent une vitesse d'absorption des stérols plus élevée que celles de la région distale (Slyven et 
Norstrom, 1970). L'augmentation de la rigidité membranaire observée dans cette région de l'intestin, et localisée selon Meddings à la superficie de la bicouche lipidique, pourrait également rendre compte de la faible perméabilité de l'iléon aux acides gras à chaîne courte ou moyenne (Meddings, 1988, 1989; Meddings et Theisen, 1989). II est connu de longue date que la plus grande partie des lipides est absorbée dans l'intestin proximal (Borgström et al, 1957; Ladman et al, 1963). Cette absorption est contrôlée par de multiples régulateurs physiologiques (Thomson et al, 1989) parmi lesquels les caractéristiques physico-chimiques des membranes luminales constituent vraisemblablement l'un des éléments essentiels.

La modulation des activités fonctionnelles de la muqueuse par la modification de la teneur en cholestérol n'implique pas toujours une perturbation de la fluidité membranaire per se (du moins telle que celle-ci est définie par les méthodes analytiques actuelles). Une étude réalisée in vitro montre en effet que l'activité spécifique de la phosphatase alcaline diminue de $20-30 \%$ si l'on augmente artificiellement la charge en cholestérol dans des membranes microvilleuses purifiées d'intestin de rat (Brasitus et al, 1988b). Mais la diminution de la fluidité membranaire, qui résulte de l'augmentation globale du rapport cholestérol/phospholipides dont la valeur, initalement proche de 1 , était amenée à 1,3 , peut être compensée, voire annulée, par l'incorporation d'alcool benzylique dans la membrane, sans que l'activité initiale de l'enzyme soit restaurée. Les activités disaccharidasiques de la bordure en brosse (saccharase, maltase et lactase) n'étaient pas modifiées par ces différents traitements. Ces observations contredisent ou relativisent les conclusions qui ont été émises par les mêmes auteurs à l'issue d'une expérience antérieure réalisée avec des rats (Brasitus et al, 1985), chez lesquels l'ingestion pendant 6 semaines d'un régime insaturé (contenant $37 \%$ en poids d'huile de maïs par comparaison avec un aliment saturé contenant $37 \%$ de beurre) a provoqué la diminution de l'index de saturation des membranes microvilleuses, l'augmentation de la fluidité membranaire, l'augmentation du contenu en acide linoléique, l'augmentation du taux de cholestérol, l'augmentation (de 2-3 fois) de l'activité de la phosphatase alcaline des bordures en brosse, ainsi que l'augmentation de l'activité de la NaK-ATPase des membranes basolatérales (dont seule la composition en acides gras a été modifiée). L'hypothèse avancée à la vue de ces résultats suggérait que l'augmentation de l'activité de la phosphatase alcaline était en corrélation avec celle de la fluidité membranaire, ce qui n'a pas été confirmé par les travaux réalisés in vitro, comme indiqué plus haut.

Ces expériences ne permettent pas d'expliquer les mécanismes par lesquels la teneur en cholestérol est capable de moduler l'activité d'enzymes membranaires. En tout état de cause, on peut remarquer que la phosphatase alcaline se distingue de la majorité des enzymes de la bordure en brosse (notamment des disaccharidases) par son mode particulier d'ancrage dans la membrane. Celui-ci implique une liaison covalente avec une molécule constitutive de la bicouche lipidique, le phosphatidylinositol (Low et Zilversmit, 1980; Chu et al, 1987, Merill, 1989), qui pourrait être à l'origine de la sensibilité de l'enzyme aux variations de composition lipidique, et donc de son classement dans le groupe des enzymes «intrinsèques» (Brasitus, 1987).

D'une façon plus générale, il est concevable que des modifications d'interactions entre lipides et segments protéiques transmembranaires puissent être induites localement par une variation de la composition 
lipidique, restreignant ou favorisant de façon spécifique la liberté de transconformation d'enzymes ou de systèmes de transport incorporés dans la matrice (Brasitus et Schachter, 1980; Mead, 1984; Yeagle, 1989). Une restriction de la capacité de changement de conformation de la NaK-ATPase serait ainsi responsable de l'inhibition exercée sur cette enzyme par des niveaux de cholestérol élevés (effet rigidifiant), tandis que l'activité de la même enzyme est stimulée par de faibles teneurs en cholestérol (revue de Yeagle, 1989). Dans ce dernier cas, l'effet activateur trouve probablement son origine dans l'établissement d'interactions directes et spécifiques entre la molécule de cholestérol et un (ou des) site(s) de l'enzyme.

\section{Biosynthèse, structure et composition des glycolipides}

La fonction physiologique des glycosphingolipides intestinaux n'est pas parfaitement définie. La partie oligosaccharidique de ces molécules participe aux caractéristiques de surface impliquées dans les interactions entre la muqueuse et diverses substances présentes dans la lumière intestinale. Certains gangliosides peuvent ainsi jouer un rôle majeur de relais transmembranaires entre des signaux de surface et le milieu intracellulaire (revue de Fishman et Brady, 1976). C'est notamment le cas d'un ganglioside monosialylé, le GM1, présent dans la plupart des membranes plasmiques des cellules eucaryotes et identifié depuis le début des années 1970 comme étant le récepteur spécifique de la toxine cholérique (Cuatrecasas, 1973a, 1973b). Divers gangliosides mono- ou polysialylés constituent une famille de récepteurs de surface reconnus par d'autres agents externes tels que des adhésines bactériennes (Kim et al, 1984;
Leffler et al, 1984; Lindahl et al, 1984), des lectines (Etzler, 1984), les toxines botulinique et tétanique (Van Heyningen, 1983; Eidels et al, 1983) ou certains virus (Markwell et al, 1984).

\section{Aspects quantitatifs et qualitatifs de l'évolution des glycolipides au cours de la différenciation}

Vingt à trente pour cent des lipides de la bordure en brosse de l'entérocyte sont des glycolipides (tableau I) dont la composition, variable selon les espèces, dépend étroitement du niveau de différenciation, et donc, de la position cellulaire le long de la villosité.

Globablement, les glycolipides contiennent $15 \%$ des hydrates de carbone constitutifs de la bordure en brosse de l'intestin grêle de rat. Chez cette espèce, le glucose et le galactose représentent, en moyenne, 44 et $35 \%$ de la quantité molaire de sucres associés aux glycolipides, le reste étant constitué de 3 à $6 \%$ de fucose, de glucosamine, de galactosamine et d'acide sialique (d'après Kim et al, 1984). La fraction lipidique de vésicules de bordure en brosse de porc contient $31 \%$ en poids de glycolipides, composés de glucosyl- et galactosylcéramides $(3 \%)$, de digalactosylcéramides $(15 \%)$, de pentahexosylcéramides fucolysés $(11 \%)$ et de gangliosides (2\%) (Christiansen et Carlsen, 1981).

Concernant l'espèce porcine, il n'existe pas d'information relative à l'évolution de la composition en glycolipides selon le niveau de différenciation cellulaire. En revanche, les travaux de Bouhours et Glickman (1976), effectués chez le rat, ont montré que la proportion de céramides glycosylés (par rapport à la quantité totale de sphingolipides cellulaires) s'élève de $74 \%$ dans les cellules des cryptes à $84 \%$ dans celles du sommet des villosités. Par ailleurs, la distribution des 3 principales fa- 
milles de glycolipides des cellules intestinales de rat, représentées par les glycosylcéramides, les trihexosylcéramides et les hématosides (du type GM3), est modifiée au cours de la progression des cellules le long de la villosité (Glickman et Bouhours 1976; Bouhours et Glickman, 1976; Breimer et al, 1981). Les résultats de Bouhours et Glickman représentés sur la figure 6A montrent que les teneurs en glucosylcéramides et en hématoside GM3 augmentent le long de l'axe cryptovillositaire, tandis que les trihéxosylcéramides sont les principaux glycolipides dont les teneurs diminuent. Les glycosphingolipides des cellules du sommet des villosités contiennent 4-5 fois plus de GM3 que ceux des cellules souches de la base des cryptes. La diminution de la teneur relative en trihexosylcéramides le long de la villosité s'effectue de façon parallèle à celle des céramides non glycosylés (figure 6A).

En résumé, la différenciation de l'entérocyte de rat s'accompagne d'une augmentation globale du taux de glycosylation des glycolipides et d'une redistribution des espèces moléculaires se traduisant par l'augmentation d'un facteur 7 du rapport GM3/ trihexosylcéramides (figure 6B).

\section{L'évolution structurale}

\section{des sphingolipides intestinaux}

au cours de la différenciation reproduitelle celle de la période périnatale?

Cette question a été soulevée par Bouhours et Bouhours (1981, 1983, 1984, 1989) qui ont entrepris de comparer les modifications des sphingolipides liées à la différenciation cellulaire chez le rat adulte à celles qui se produisent au cours de la gestation et du développement postnatal de la muqueuse intestinale. En raison de la fragilité de l'épithélium intestinal du rat
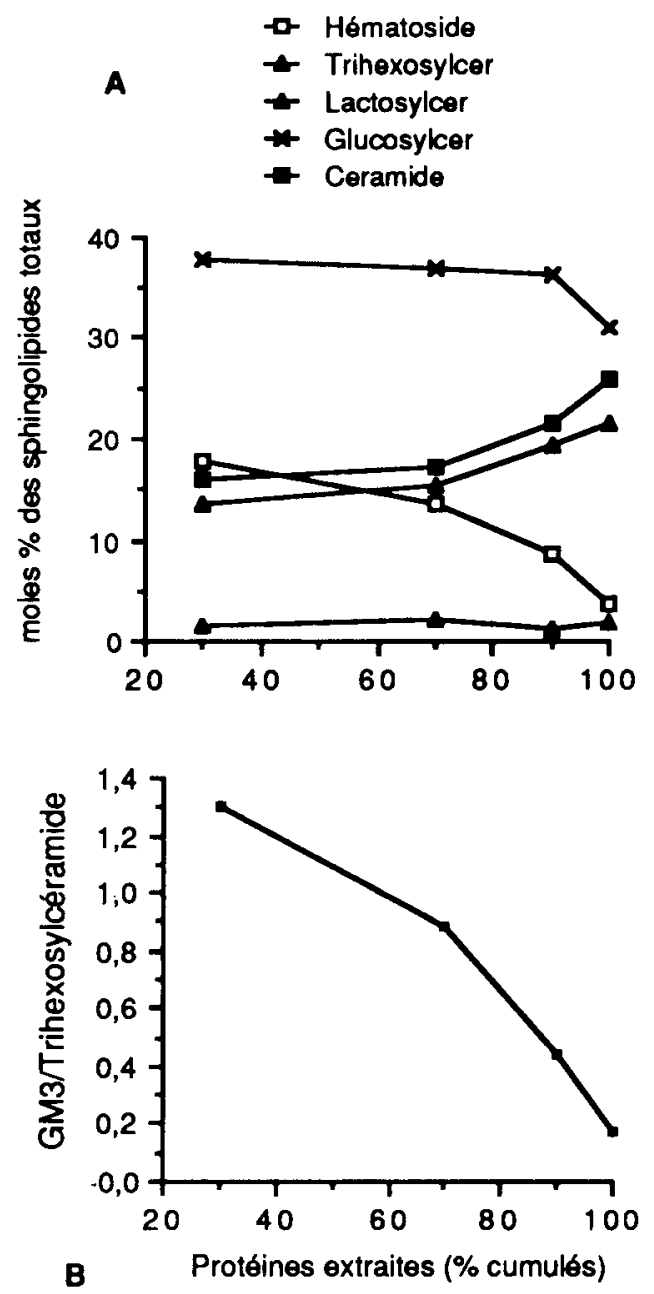

Sommet

Cryptes

Fig 6. A. Évolution des teneurs relatives des différentes classes de sphingolipides (hématosides, trihexosylcéramides, lactosylcéramides, glucosylcéramides, et céramides) le long de l'axe crypto-villositaire de l'intestin de rat, depuis la base des cryptes jusqu'au sommet des villosités. B. Evolution du rapport molaire hématoside GM3/trihexosylcéramides le long de l'axe cryptovillositaire. Graphes adaptés des résultats de Bouhours et Glickman (1976). 
nouveau-né qui rend très difficile la séparation des différentes populations cellulaires, les analyses ont été réalisées sur la muqueuse entière.

\section{Glycolipides totaux :}

Le contenu total en glycosphingolipides intestinaux est multiplié par 3 au cours des 6 derniers j précédant la parturition pour atteindre un niveau maximal à la naissance (fig 7A). Cette brusque poussée prénatale des glycolipides s'accompagne d'importants remaniements de la distribution des différentes espèces moléculaires (fig 7B). Ceux-ci se traduisent notamment par l'augmentation des proportions en glucosylcéramides et en hématosides. Dans le même temps, la proportion de sphingolipides non glysocylés (céramides) diminue. Ces modifications qualitatives rappellent celles qui se produisent au cours de la différenciation crypto-villositaire chez l'adulte. Elles semblent correspondre à la phase de morphogenèse intense de l'intestin qui s'effectue entre le $18^{\mathrm{e}} \mathrm{j}$ de gestation et la naissance (Kédinger et al, 1986a). La maturation fonctionnelle proprement dite débute et se déroule après la naissance, période qui correspond cette fois à une diminution progressive du contenu total en glycolipides. Celui-ci est donc maximal à la naissance et atteint un niveau 4 fois moins élevé après $30 \mathrm{j}$ de vie post partum (fig 7A).

Hématoside GM3, trihexosylcéramides et lactosylcéramides:

À la naissance, le contenu intestinal en GM3, qui représente alors $25 \%$ des sphingolipides totaux et $85 \%$ des gangliosides, est près de 7 fois plus élevé que celui du rat adulte ou âgé de $30 \mathrm{j}$. La concentration en trihexosylcéramides suit une évolution inverse (augmentation d'un facteur 1,4 entre 0 et $30 \mathrm{j}$ ), de sorte que les profils d'évolution du rapport molaire GM3/ trihexoxylcéramides au cours de la diffé- renciation chez l'adulte (augmentation de 0,2 à 1,3 - fig 6B) et au cours du développement postnatal (diminution de 9,5 à 1 fig $7 \mathrm{C}$ ) sont opposés. L'augmentation de la teneur relative en trihexosylcéramides, visible dès le $15^{e} \mathrm{j}$ après la naissance, coïncide avec la diminution de la proportion de lactosylcéramides (fig 7B). Ceci suggère que l'activité de la galactosyltransférase intestinale se déclenche entre la première et la deuxième semaine de développement du nouveau-né.

Glucosylcéramides :

Quel que soit le stade de développement ou de différenciation cellulaire, les glucosylcéramides représentent la principale classe de glycolipides dans l'intestin de rat. Leur teneur relative, proche de $50 \%$ à la naissance, n'atteint plus que 35\% chez le rat adulte ou âgé de $30 \mathrm{j}$ (fig 7B). Cette évolution est également l'image inversée de ce qui est observé au cours de la différenciation le long de l'axe cryptovillositaire chez l'adulte (comparer les fig $6 A$ et $7 B$ ).

Par ailleurs, la structure de l'acide sialique du GM3 dépend de la maturation post-natale de l'intestin: l'acide $\mathrm{N}$-acétylneuraminique, essentiellement présent à la naissance, est progressivement remplacé, à partir du sevrage, par l'acide $\mathrm{N}$ glycolylneuraminique résultant de l'action d'une $\mathrm{N}$-acétyl-hydroxylase sur le précurseur néonatal (Bouhours et Bouhours, 1983, 1989). L'acide N-glycolylneuraminique représente finalement le principal acide sialique contenu dans le GM3 de l'épithétium intestinal du rat adulte.

Enfin, certaines modifications liées à la maturation postnatale ont trait à la nature des acides gras constitutifs des glycolipides. Cet aspect sera abordé dans la dernière partie de cette étude.

II est clair qu'une réorganisation complète des sphingolipides entérocytaires se 
A

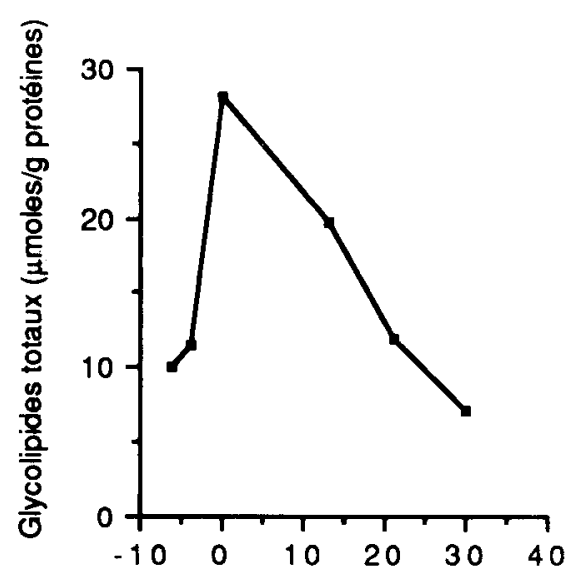

C

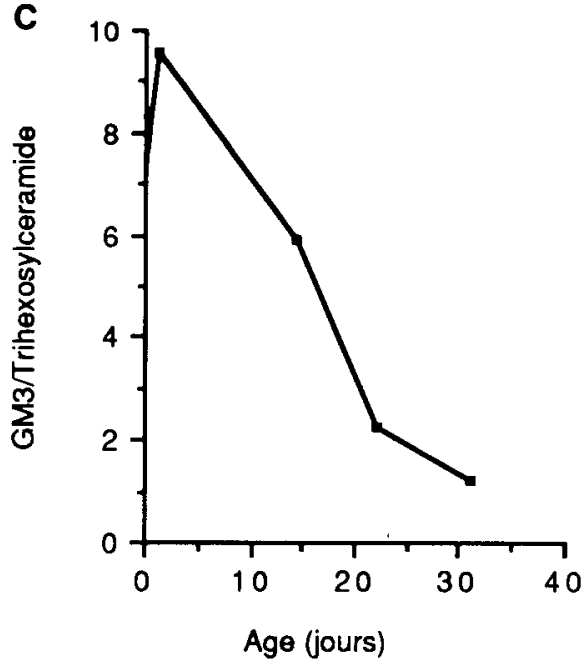

B

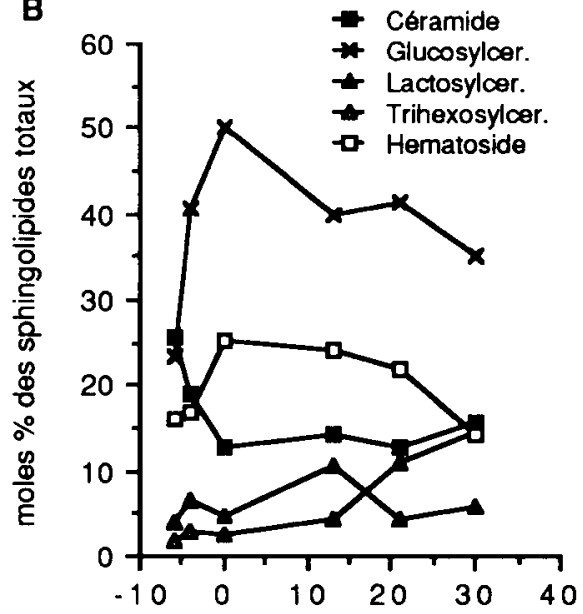

Fig 7. A. Évolution de la concentration en glycolipides totaux dans l'épithélium intestinal du jeune rat, depuis le $17^{\mathrm{e}} \mathrm{j}$ de gestation jusqu'à l'âge de $30 \mathrm{j}$. B. Evolution des teneurs relatives des principales classes de sphingolipides depuis le $17^{\circ} \mathrm{j}$ de gestation jusqu'à l'âge de $30 \mathrm{j}$ (au $17^{\circ} \mathrm{j}$ de gestation, les gangliosides autres que le GM3 rat représentent $20 \%$ du total). C. Évolution du rapport molaire hématoside GM3/trihexosylcéramides depuis le $17^{\mathrm{e}} \mathrm{j}$ de gestation jusqu'à l'âge de $30 \mathrm{j}$. Graphes adaptés des résultats de Bouhours et Bouhours (1981).

produit au cours de la période périnatale. Cette restructuration précède ou accompagne l'insertion de nouvelles protéines dans la bordure en brosse, telles que la sucrase-isomaltase et la forme mature de la phosphatase alcaline, et participe vrai- 
semblablement à la mise en place des fonctions de barrière spécifiques de l'adulte. L'ensemble de ces données permet de conclure que, si les cellules des cryptes de l'intestin de rat adulte ne peuvent pas être assimilées à des cellules fœtales (Bouhours et Bouhours, 1981), une certaine analogie existe entre l'évolution prénatale (morphogenèse) et l'évolution crypto-villositaire (différenciation). Du point de vue de l'évolution des sphingolipides, ces 2 phases se caractérisent par l'augmentation des teneurs relatives en glucosylcéramides et hématosides, tandis que celle des céramides (non glycosylés) diminue. En revanche, les évolutions liées à la maturation postnatale et à la différenciation crypto-villositaire sont opposées.

\section{Évolution et régulation des activités de synthese}

\section{Activités glycosyltransférase et sialyltrans-} férase au cours de la différenciation

L'évolution du rapport entre les proportions molaires de GM3 et de trihexosylcéramides (fig 6B), 2 familles de glycolipides dérivant d'un précurseur biochimique commun, les lactosylcéramides, suggère que la substitution progressive de l'activité galactosyltransférase par l'activité sialyltransférase peut être un élément important des processus de différenciation de l'entérocyte de rat adulte. En mesurant in vitro l'activité spécifique de la sialyltransférase dans les différentes fractions cellulaires incubées en présence de lactosylcéramide, Glickman et Bouhours (1976) ont constaté que cette activité est multipliée par 100 dans les cellules du sommet des villosités par rapport aux cellules de la base des cryptes. Inversement, l'activité galactosyltransférase (vis-à-vis du même substrat) mesurée dans les cellules matures ne représente plus que $10-30 \%$ de l'activité présente initialement dans les cellules des cryptes (Bouhours et Glickman, 1976). La diminution de la synthèse de trihexosylcéramides pourrait correspondre à l'abandon du cycle cellulaire de prolifération (Bouhours et Glickman, 1976), tandis que l'augmentation de la teneur en hématoside à la surface des cellules différenciées serait susceptible de faciliter les dissociations intercellulaires nécessaires à l'extrusion des cellules matures parvenant au sommet des villosités (Breimer et al, 1981).

\section{Localisation subcellulaire de l'acide sialique}

La haute spécificité de la lectine de Limax flavus pour l'acide sialique a permis de visualiser, par marquage cytochimique des villosités intestinales de rat, l'évolution de la distribution subcellulaire de l'acide sialique en fonction du niveau de différenciation (Taatjes et Roth, 1988). Les composants sialylés (glycolipidiques et glycoprotéiques) apparaissent uniformément répartis dans les membranes golgiennes, basolatérales et apicales des cellules souches des cryptes, mais l'intensité du marquage des membranes basolatérales par la lectine décroît au fur et à mesure de la progression des cellules vers la partie supérieure des cryptes. Dans les cellules matures de la partie supérieure des villosités, seule la bordure en brosse reste fortement marquée. L'une des hypothèses avancées par les auteurs suggère que, lors du turn-over des constituants membranaires des cellules matures, les réactions de sialylation des glycolipides et des glycoprotéines sont essentiellement destinées aux composants de la bordure en brosse, ceux des membranes basolatérales n'étant plus concernés. L'existence d'un mécanisme analogue a également été suggérée dans le cas des glycoprotéines fucosylées, qui sont préférentiellement incorporées dans la bordure en brosse des cellules matures (Quaroni et al, 1980). La redistribu- 
tion sélective de certains glycoconjugués vers la bordure en brosse permettrait d'établir la polarisation cellulaire et de la maintenir pendant la durée de vie de l'entérocyte, malgré le renouvellement permanent de ses structures membranaires de surface. La présence d'acide sialique dans les membranes basolatérales pourrait alors être considérée comme un marqueur précoce des cellules épithéliales indifférenciées (Taatjes et Roth, 1988).

\section{Régulation des activités de glycosylation des sphingolipides}

Un ensemble de résultats obtenus par l'équipe de Brasitus suggère que l'un des mécanismes de régulation de la glycosylation des sphingolipides pourrait impliquer les propriétés physico-chimiques des membranes de l'appareil de Golgi. En injectant de la dexaméthasone à des rats, ces chercheurs ont obtenu une modification de la composition lipidique, de la fluidité et des activités glycosphingolipide glycosyltransférases des membranes golgiennes provenant d'entérocytes extraits de l'intestin proximal de rat adulte (Dudeja et al, 1988). Brièvement, le traitement par la dexaméthasone a pour effet d'augmenter la proportion d'acides gras polyinsaturés contenus dans les phospholipides de la bordure en brosse (Brasitus et al, 1987) et des membranes golgiennes (Dudeja et al, 1988), d'augmenter la fluidité membranaire estimée par les techniques de polarisation de fluorescence (Brasitus et al, 1987; Dudeja et al, 1988), d'augmenter les activités spécifiques de la galactosyltransférase et de la sialyltransférase vis-à-vis d'un lactosylcéramide exogène (Dudeja et al, 1988) et, finalement, de modifier la composition globale des glycosphingolipides de la muqueuse intestinale (Dahiya et Brasitus, 1987). En outre, l'activité lactosylcéramide galactosyltransférase de membranes golgiennes provenant d'entérocytes de rats non traités peut être aug- mentée in vitro par l'incorporation d'alcool benzylique (Dudeja et al, 1988) dont l'effet fluidifiant vis-à-vis des membranes biologiques est connu (Gordon et al, 1980). En revanche, l'activité lactosylcéramide sialyltransférase n'est pas modifiée par ce dernier traitement. L'hypothèse avancée par Brasitus et ses collaborateurs attribue à la dexaméthasone la capacité de moduler les activités glycosphingolipide glycosyltransférases via l'induction in vivo de modifications de l'environnement lipidique de ces enzymes. Les résultats différents obtenus in vitro avec la galactosyitransférase et la sialyltransférase suggèrent cependant que les modifications d'activités enzymatiques induites in vivo par la dexaméthasone ne sont pas nécessairement en corrélation avec une augmentation de la fluidité membranaire. En tout état de cause, les résultats obtenus dans ces diverses expériences étayent l'hypothèse selon laquelle les glucocorticoïdes exercent, d'une part, un effet régulateur sur la composition lipidique des membranes biologiques et, d'autre part, jouent un rôle prépondérant dans la mise en place des propriétés de surface des cellules intestinales.

Évolution de la composante lipidique des glycolipides : I'hydroxylation des acides gras

Une étude utilisant la spectrométrie de masse a démontré que, chez le rat, la partie lipidique (céramide) de certains glycosphingolipides subit, elle aussi, une modification au cours de la différenciation (Breimer et al, 1982). Celle-ci se traduit principalement par une augmentation du taux d'acides gras hydroxylés contenus dans les glucosylcéramides des cellules matures comparativement aux cellules des cryptes. L'hydroxylation des acides gras constitutifs de l'hématoside GM3 ne semble pas liée au stade de différenciation cellulaire, mais plutôt à celui de la matura- 
tion postnatale de la muqueuse : pendant les 3 premières semaines de vie néonatale, ce ganglioside contient uniquement des acides gras non hydroxylés (Bouhours et Bouhours, 1983). L'hématoside de l'entérocyte de rat adulte contient principalement des acides gras hydroxylés, quelle que soit la position cellulaire le long de la villosité (Bouhours et Glickman, 1977; Breimer et al, 1982). Soixante-dix à soixante-quinze pour cent des acides gras associés aux glycosphingolipides de l'épithélium intestinal sont ainsi hydroxylés (Bouhours et Glickman, 1977). Chez le rat, le déclenchement du processus d'hydroxylation s'effectuerait au moment du sevrage. Dans le cas d'espèces à gestation plus longue comme l'homme, l'hydroxylation du GM3 se produirait au cours du développement fœtal (Bouhours et Bouhours, 1983). II est à noter que les gangliosides du cerveau de rat ne contiennent que des acides gras non hydroxylés (Sambasivaro et McCluer, 1964). Un système d'hydroxylation des acides gras des galactosylcéramides existe dans le cerveau de jeune rat, mais son niveau d'activité diminue rapidement après le sevrage (Murad et al, 1976).

Les modifications des autres glycosphingolipides intestinaux se traduisent, d'une façon générale, par l'élévation du taux d'hydroxylation et par l'élongation des chaînes d'acides gras au fur et à mesure de la migration entérocytaire (Breimer et al, 1982). La chaîne hydrocarbonée de la molécule initiale de sphingosine (4Dhydroxysphinganine ou phytosphingosine) est présente dans les glycolipides intestinaux dès la naissance et subit peu de modification ultérieure, aussi bien chez l'homme que chez les rongeurs ou d'autres espèces (Breimer et al, 1982; Bouhours et Bouhours, 1983). La synthèse de 4D-hydroxysphinganine, base commune des glycolipides intestinaux, se produirait donc à un stade relativement précoce du développement fœtal des différentes espèces. Chez le rat, la 4Dhydroxysphinganine intestinale est détectée dès le $17^{\circ} \mathrm{j}$ de gestation (Bouhours et Bouhours, 1984).

La modification de la nature des acides gras constitutifs des glycosphingolipides pourrait se produire, soit par un turn-over complet de ces molécules, soit par un remodelage spécifique de la partie lipidique permettant le remplacement progressif des acides gras non hydroxylés par des acides gras hydroxylés (Breimer et al, 1982). Les conséquences physiologiques de telles modifications, qui semblent spécifiques de l'épithélium intestinal, ne sont pas solidement établies. On peut concevoir que les propriétés dynamiques d'ancrage et de mouvements latéraux des antigènes de surface portés par les glycolipides dépendent des caractéristiques structurales du céramide ancré dans la bicouche (ainsi, bien entendu, que celles de la matrice lipidique elle-même). II a été suggéré (Breimer et al, 1982) que l'augmentation du nombre de groupements hydroxyles portés par les acides gras constitutifs de la partie céramide favoriserait l'établissement de ponts hydrogène latéraux entre glycolipides incorporés dans la bicouche, contribuant ainsi à stabiliser les structures membranaires de l'entérocyte au moment où la cellule émerge de l'embouchure des cryptes et s'expose au contenu intestinal.

\section{CONCLUSION}

La muqueuse de l'intestin grêle constitue le principal site d'absorption et de transformation des nutriments, fonctions essentielles à l'organisme, susceptibles d'être modulées par la qualité des aliments ingérés. Le renouvellement permanent des cellules intestinales nécessite une activité de biosynthèse des membranes cellulaires 
d'autant plus intense que le remplacement des membranes plasmiques luminales endommagées s'effectue plus rapidement que celui de la cellule elle-même. Les composants de la matrice lipidique sont nécessairement soumis à des mécanismes de régulation complexes, qui englobent l'incidence de l'apport exogène tout en assurant le maintien de l'intégrité, de la polarité et des fonctions cellulaires pendant la courte durée de vie des cellules intestinales. Dès la fin de la période de sevrage, les cellules des cryptes constituent une population spécifique de cellules souches qui, en migrant depuis leur site de prolifération, achèveront de se différencier et acquéreront en quelques heures les caractéristiques nécessaires aux fonctions de digestion et d'absorption de la muqueuse intestinale mature.

Il est clair que la muqueuse de l'intestin grêle est une structure particulièrement $d y$ namique, dont les caractéristiques biochimiques et fonctionnelles évoluent aussi bien dans l'espace (axe crypto-villositaire, localisation sur la longueur de l'intestin) que dans le temps (maturation postnatale et postsevrage, vieillissement). Le dénominateur commun de ces évolutions semble être la rigidification des membranes apicales et basolatérales, tant en ce qui concerne la différenciation cellulaire chez l'adulte, que la maturation de la muqueuse chez le nouveau-né. La détermination des modifications fonctionnelles directement concernées par ce processus et la mise en évidence de l'incidence des lipides alimentaires sur l'ensemble de ces évolutions constituent l'une des voies à explorer dans le domaine des recherches fondamentales en nutrition.

\section{REMERCIEMENTS}

TS Arfi est boursier de la Fondation Française pour la Nutrition. JM Allessandri exprime toute sa sympathie et ses remerciements à $P$ Guesnet pour sa lecture critique du premier manuscrit.

\section{RÉFÉRENCES}

Alessandri JM, Arfi TS, Thévenoux J, Léger CL (1990) Diet-induced alterations of lipids during cell differentiation in the small intestine of growing rats: effect of an essential fatty acid deficiency. $J$ Pediatr Gastroenterol Nutr 10, 504-515

Borgström B, Dahlquist A, Lundh G, Sjovall J (1957) Studies of intestinal digestion and absorption in the human. J Clin Invest 36, 15211536

Boucrot $P$ (1983) Digestion et absorption intestinale des phosphatidylcholines. Reprod Nutr Dev 23, 943-958

Bouhours JF, Glickman RM (1976) Rat intestinal glycolipids. II. Distribution and biosynthesis of glycolipids and ceramide in villus and crypt cells. Biochim Biophys Acta 441, 123-133

Bouhours JF, Glickman RM (1977) Rat intestinal glycolipids. III. Fatty acids and long chain bases of glycolipids from villus and crypt cells. Biochim Biophys Acta 487, 51-60

Bouhours D, Bouhours JF (1981) Developmental changes of rat intestinal glycolipids. Biochem Biophys Res Commun 99, 1384-1389

Bouhours D, Bouhours JF (1983) Developmental changes of hematoside of rat small intestine. Postnatal hydroxylation of fatty acids and sialic acid. $J$ Biol Chem 258, 299-304

Bouhours D, Bouhours JF (1984) Phytosphingosine in intestinal glycolipids of the rat fetus. Biochim Biophys Acta 794, 169-171

Bouhours JF, Bouhours D (1989) Hydroxylation of CMP-NeuAC controls the expression of $\mathrm{N}$ glycolyineuraminic acid in GM3 ganglioside of the small intestine of inbred rats. $J$ Biol Chem 264, 16992-16999

Brasitus TA (1987) Modulation of intestinal transport processes by dietary cholesterol and triacylglycerols (editorial). J Pediatr Gastroenterol Nutr 6, 657-659

Brasitus TA, Schachter D (1980) Lipid dynamics and lipid-protein interactions in rat enterocyte basolateral and microvillus membranes. Biochemistry 19, 2763-2769 
Brasitus TA, Schachter D (1982) Cholesterol biosynthesis and modulation of membrane cholesterol and lipid dynamics in rat intestinal microvillus membranes. Biochemistry 21 , 2241-2246

Brasitus TA, Yeh KY, Holt PR, Schachter D (1984) Lipid fluidity and composition of intestinal microvillus membranes isolated from rats of different ages. Biochim Biophys Acta 778, 341-348

Brasitus TA, Dudeja PK (1985) Alterations in the physical state and composition of brush border membrane lipids of rat enterocytes during differentiation. Arch Biochem Biophys 240, 483-488

Brasitus TA, Davidson NO, Schachter D (1985) Variations in dietary triacylglycerol saturation alter the lipid composition and fluidity of rat intestinal plasma membranes. Biochim Biophys Acta 812, 460-472

Brasitus TA, Dudeja PK, Dahiya R, Halline A (1987) Dexamethasone-induced alterations in lipid composition and fluidity of rat proximal-small-intestinal brush-border membranes. Biochem J 248, 455-461

Brasitus TA, Dahiya R, Dudeja PK (1988a) Rat proximal small intestinal Golgi membranes: lipid composition and fluidity. Biochim Biophys Acta 958, 218-226

Brasitus TA, Dahiya R, Dudeja PK, Bissonnette B (1988b) Cholesterol modulates alkaline phosphatase activity of rat intestinal microvillus membranes. $J$ Biol Chem 263, 85928597

Breimer ME, Hansson GC, Karlsson KA, Leffler $H(1981)$ Glycosphingolipids and the differentiation of intestinal epithelium. Exp Cell Res $135,1-13$

Breimer ME, Hansson GC, Karlsson KA, Leffler $H$ (1982) Studies on differentiating epithelial cells of rat small intestine. Alterations in the lipophilic part of glycosphingolipids during cell migration from crypt to villus tip. Biochim Biophys Acta 710, 415-427

Brenner RR (1984) Effect of unsaturated acids on membrane structure and enzyme kinetics. Prog Lipid Res 23, 69-96

Brown MS, Goldstein JL (1980) Multivalent feedback regulation of HMG CoA reductase, a control mechanism coordinating isoprenoid synthesis and cell growth. J Lipid Res 21, 505-517
Chapelle S, Gilles-Baillien M (1983) Phospholipids and cholesterol in brush border and basolateral membranes from rat intestinal mucosa. Biochim Biophys Acta 753, 269-271

Christiansen K, Carlsen J (1981) Microvillus membrane vesicles from pig small intestine. Purity and lipid composition. Biochim Biophys Acta 647, 188-195

Chu SHW, Walker WA (1988) Development of the gastrointestinal mucosal barrier: changes in phospholipid head groups and fatty acid composition of intestinal microvillus membranes from newborn and adult rats. Pediatr Res 23, 439-442

Chu SHW, Geyer RP, Walker WA (1987) myoInositol action on gerbil intestine: alterations in alkaline phosphatase activity upon phosphadylinositol depletion and repletion in vivo. Biochim Biophys Acta 929, 220-225

Clandinin MT, Field CJ, Hargreaves K, Morson L, Zsigmond E (1985) Role of diet fat in subcellular structure and function. Can $J$ Physiol Pharmacol 63, 546-556

Cuatrecasas P (1973a) Interaction of Vibrio cholerae enterotoxin with cell membranes. Biochemistry 12, 3547-3557

Cuatrecasas P (1973b) Gangliosides and membrane receptors for cholera toxin. Biochemistry 12, 3558-3566

Dahiya R, Brasitus TA (1987) Dexamethasoneinduced alterations in the glycosphingolipids of rat proximal small-intestinal mucosa. Biochim Biophys Acta 922, 118-124

Dietschy JM, Siperstein MD (1965) Cholesterol synthesis by the gastrointestinal tract: localization and mechanisms of control. $J$ Clin Invest $44,1311-1327$

Dudeja PK, Brasitus TA (1987) Identification and partial characterization of phospholipid methylation in rat small-intestinal brushborder membranes. Biochim Biophys Acta $919,307-310$

Dudeja PK, Dahiya R, Brown MD, Brasitus TA (1988) Dexamethasone influences the lipid fluidity, lipid composition and glycosphingolipid glycosyltransferase activities of rat proximal-small-intestinal Golgi membranes. Biochem J 253, 401-408

Dudeja PK, Harig JM, Ramaswamy K, Brasitus TA (1989) Protein-lipid interactions in human small intestinal brush-border membranes. Am J Physio/ 257, G809-G817 
Eidels L, Proia RL, Hart DA (1983) Membrane receptors for bacterial toxins. Microbiol Rev 47, 596-620

Engelhardt EL, Neu J, Sankar MB, Gimotty PA, Meyer JW (1989) Changes in phospholipid and cholesterol concentrations of the rat microvillus membrane during maturation. $J \mathrm{Pe}$ diatr Gastroenterol Nutr 9, 89-93

Etzler ME (1984) Lectin receptors on the intestinal cell surface. In: Attachment of Oganisms to the Gut Mucosa, volume II (Boedeker EC, ed) CRC Press Inc, Boca Raton, Florida, 147-156

Fairbanks KP, Witte LD, Goodman DS (1984) Relationship between mevalonate and mitogenesis in human fibroblasts stimulated with platelet-derived growth factor. $J \mathrm{Biol}$ Chem 259, 1546-1551

Fishman PH, Brady RO (1976) Biosynthesis and function of gangliosides. Science 194, 906915

Garg ML, Keelan M, Wierzbicki A, Thomson ABR, Clandinin MT (1988) Regional differences in lipid composition and incorporation of saturated and unsaturated fatty acids into microsomal membranes of rat small intestine. Can J Physiol Pharmacol 66, 794-800

Glickman RM, Bouhours JF (1976) Characterization, distribution and biosynthesis of the major ganglioside of rat intestinal mucosa. Biochim Biophys Acta 424, 17-25

Gordon LM, Sauerheber RD, Esgate JA, Dipple I, Marchmont RJ, Houslay MD (1980) The increase in bilayer fluidity of rat liver plasma membranes achieved by the local anesthetic benzyl alcohol affects the activity of intrinsic membrane enzymes. J Biol Chem 255, 45194527

d'Harlingue AE, Kwong LK, Morill JS, Sunshine P, Tsuboi KK (1986) Growth and differentiative maturation of the rat enterocyte. $J \mathrm{Pe}$ diatr Gastroenterol Nutr 5, 956-963

Hart MH, Grandjean CJ, Park JHY, Erdman SH, Vanderhoof JA (1988) Essential fatty acid deficiency and postresection mucosal adaptation in the rat. Gastroenterology 94, 682-687

Heyman M, Crain-Denoyelle AM, Desjeux JF (1989) Endocytosis and processing of protein by isolated villus and crypt cells of the small intestine. J Pediatr Gastroenterol Nutr 9, 238245
Holmes RP, Kummerow FA (1985) The effect of dietary lipids on the composition and properties of biological membranes. In: Structure and Properties of Cell Membranes, vol 3 (Benga G, ed) CRC Press Inc, Boca Raton, Florida, 261-280

Iglesias J, Gonzalez-Pacanowska D, Castillo M, Garcia-Peregrin E (1989) Localization of acyl-coenzyme A: cholesterol acyltransferase in villus and crypt cells of chick intestine. Biochem Cell Biol 67, 93-97

Kaneko I, Hazama-Shimada Y, Endo A (1978) Inhibitory effects on lipid metabolism in cultured cells of ML-236B, a potent inhibitor of 3hydroxy-3-methylglutaryl coenzyme A reductase. Eur J Biochem 87, 313-321

Kédinger $M$, Haffen $K$, Simon-Assmann $P$ (1986a) Control mechanisms in the ontogenesis of villus cells. In: Molecular and Cellular Basis of Digestion (Desnuelle P, Sjöström $\mathrm{H}$, Noren O, eds) Elsevier, Amsterdam, 323-334

Kédinger $M$, Simon-Assmann $P$, Lacroix $B$ (1986b) Développement de la fonction digestive : régulation de la maturation des enzymes de la bordure en brosse intestinale. Reprod Nutr Dev 26, 691-702

Kim YS, Morita A, Miura S, Siddiqui B (1984) Structure of glycoconjugates of intestinal mucosal membranes: role in bacterial adherence. In: Attachment of Organisms to the Gut Mucosa, volume II (Boedeker EC, ed), CRC Press Inc, Boca Raton, Florida, 99-109

Klein RM, McKenzie JC (1983) The role of cell renewal in the ontogeny of the intestine. I. Cell proliferation patterns in adult, fetal, and neonatal intestine. $J$ Pediatr Gastroenterol Nutr 2, 10-43

Ladman AJ, Padykula HA, Strauss EW (1963) A morphological study of rat transport in the normal human jejunum. Am J Anat 112, 389419

Leblond CP (1981) The life history of cells in renewing systems. Anat Rec 114-158

Leffler H, Svanborg-Eden C, Schoolnik G, Wadström $T$ (1984) Glycosphingolipids as receptors for bacterial adhesion: host glycolipid diversity and other selected aspects. In: Attachment of Organisms to the Gut Mucosa, volume II (Boedeker EC, ed), CRC Press Inc, Boca Raton, Florida, 177-187

Lindahl M, Faris A, Wadström T (1984) A GM2like receptor for CFAl and K99. In: Attache- 
ment of Organisms to the Gut Mucosa, volume II (Boedeker EC, ed) CRC Press Inc, Boca Raton, Florida, 189-195

Low MG, Zilversmit DB (1980) Role of phosphatidylinositol in attachment of alkaline phosphatase to membranes. Biochemistry 19, 3913-3918

McMurchie EJ (1988) Dietary lipids and the regulation of membrane fluidity and function. In: Advances in membrane fluidity, vol 3: Physiological Regulation of Membrane Fluidity (Aloia RC, Curtain CC, Gordon LM, eds) Alan R Liss Inc, New York, 189-237

Madara JL, Trier JS, Neutra MR (1980) Structural changes in the plasma membrane accompanying differentiation of epithelial cells in human and monkey small intestine. Gastroenterology 78, 963-975

Maltese WA (1984) Induction of differentiation in murine neuroblastoma cells by mevinolin, a competitive inhibitor of 3-hydroxy-3methylglutaryl coenzyme A reductase. Biochem Biophys Res Commun 120, 454-460

Markwell MAK, Fredman P, Svennerholm L (1984) Receptor ganglioside conterit of three hosts for Sendai virus, MDBK, HeLa, and MDCK cells. Biochim Biophys Acta 775, 7-16

Mead JF (1984) The non-eicosanoid functions of the essential fatty acids. $J$ Lipid Res 25 , 1517-1521

Meddings JB (1988) Lipid permeability of rat jejunum and ileum : correlation with physical properties of the microvillus membrane. Biochim Biophys Acta 943, 305-314

Meddings JB (1989) Lipid permeability of the intestinal microvillus membrane may be modulated by membrane fluidity in the rat. Biochim Biophys Acta 984, 158-166

Meddings JB, Theisen S (1989) Development of rat jejunum : lipid permeability, physical properties, and chemical composition. Am $J$ Physiol 256, G931-G940

Merrill AH (1989) Lipid modulators of cell function. Nutr Rev 47, 161-169

Mooseker MS, Howe CL (1982) The brush border of intestinal epithelium : a model system for analysis of cell-surface architecture and motility. In: Methods in Cell Biology vol 25: The Cytoskeleton. Part B. Biological Systems and in Vitro Models. (Wilson L, ed), Santa Barbara, 143-174
Murad S, Strycharz GD, Kishimoto $Y(1976) \alpha$ hydroxylation of lignoceric and nervonic acids in the brain. Effects of altered thyroid function on postnatal development of the hydroxylase activity. J Biol Chem 251, 5237-5241

Neu J, Ozaki CK, Angelides KJ (1986) Glucocorticoid-mediated alteration of fluidity of brush border membrane in rat small intestine. Pediatr Res 20, 79-82

Noren $O$, Sjöström $H$, Danielsen $E M$, Cowell GM, Skovbjerg H (1986) The enzymes of the enterocyte plasma membrane. In: Molecular and Cellular Basis of Digestion (Desnuelle P, Sjöström H, Noren O, eds) Elsevier, Amsterdam, 335-365

Norum KR, Helgerud P, Peterson LB, Grool PHE, De Jonge HR (1983) Influence of diets on acyl-CoA: cholesterol acyltransferase and on acyl-CoA: retinol acyltransferase in villus and crypt cells from rat small intestinal mucosa and in the liver. Biochim Biophys Acta 751, 153-161

O'Doherty PJA (1978) Phospholipid synthesis in differentiating cells of rat intestine. Arch Biochem Biophys 190, 508-513

O'Doherty PJA, Smith NB, Kuksis A (1977) Stimulation of CDP-choline biosynthesis by enantiomeric lysophosphatidylcholines in rat intestinal mucosa. Arch Biochem Biophys $180,10-18$

Pang KY, Bresson JL, Walker WA (1983) Development of the gastrointestinal mucosal barrier. Evidence of structural differences in microvillus membranes from newborn and adult rabbits. Biochim Biophys Acta 727, 201-208

Pang KY, Newman AP, Udall JN, Walker WA (1985) Development of the gastrointestinal mucosal barrier. VII. In utero maturation of microvillus surface by cortisone. Am J Physiol 249, G85-G91

Quaroni A, Kirsch K, Herscovics A, Isselbacher KJ (1980) Surface-membrane biogenesis in rat intestinal epithelial cells at different stages of maturation. Biochem J 192, 133-144

Quesney-Huneeus V, Wiley MH, Siperstein MD (1979) Essential role for mevalonate synthesis in DNA replication. Proc Natl Acad Sci USA 76, 5056-5060

Quesney-Huneeus V, Galick HA, Siperstein MD, Erickson SK, Spencer TA, Nelson JA (1983) The dual role of mevalonate in the cell cycle. J Biol Chem 258, 378-385 
Rasmussen $\mathrm{H}$, Matsumoto $T$, Fontaine $\mathrm{O}$, Goodman DBP (1982) Role of changes in membrane lipid structure in the action of 1,25dihydroxyvitamin D3. Federation Proc 41, 7277

Sambasivarao K, McCluer RH (1964) Lipid components of gangliosides. J Lipid Res 5, 103108

Sandermann Jr H (1978) Regulation of membrane enzymes by lipids. Biochim Biophys Acta 515, 209-237

Schachter D, Shinitzky M (1977) Fluorescence polarization studies of rat intestinal microvillus membranes. J Clin Invest 59, 536-548

Schneider AG, Stange EF (1987) Evidence for the compartimentalization of cholesterol in cultured intestinal cells (abstract). Gastroenterology 92, 1624

Schwarz SM, Ling S, Hostetler B, Draper JP, Watkins JB (1984) Lipid composition and membrane fluidity in the small intestine of the developing rabbit. Gastroenterology 86, 1544-1551

Schwarz SM, Hostetler B, Ling S, Mone M, Watkins JB (1985) Intestinal membrane lipid composition and fluidity during development in the rat. Am J Physiol 248, G200-G207

Schwarz SM, Bostwick HE, Danziger MD, Newman LJ, Medow MS (1989) Ontogeny of basolateral membrane lipid composition and fluidity in small intestine. Am J Physiol 257, G138-G144

Siperstein MD (1984) Role of cholesterogenesis and isoprenoid synthesis in DNA replication and cell growth. $J$ Lipid Res 25, 1462-2468

Slyven C, Nordstrom C (1970) The site of absorption of cholesterol and sitosterol in rat small intestine. Scand J Gastroentero/ 5, 5763

Snipes RL (1967) Cellular dynamics in the jejunum of essential fatty acid deficient mice. Anat Rec 159, 421-430

Snipes RL (1968) The effects of essential fatty acid deficiency on the ultrastructure and functional capacity of the jejunal epithelium. Lab Invest 18, 179-189

Spady DK, Dietschy JM (1983) Sterol synthesis in vivo in 18 tissues of the squirrel monkey, guinea pig, rabbit, hamster and rat. I Lipid Res 24, 303-315
Srere PA, Chaikoff IL, Dauben WC (1948) The in vitro synthesis of cholesterol from acetate by surviving adrenal cortical tissue. J Biol Chem 176, 829-833

Stange EF, Dietschy JM (1983a) Absolute rates of cholesterol synthesis in rat intestine in vitro and in vivo: a comparison of different substrates in slices and isolated cells. $J$ Lipid Res 24, 72-82

Stange EF, Dietschy JM (1983b) Cholesterol synthesis and low density lipoprotein uptake are regulated independently in rat small intestinal epithelium. Proc Natl Acad USA 80, 5739-5743

Stange EF, Dietschy JM (1985) The origin of cholesterol in the mesenteric lymph of the rat. J Lipid Res 26, 175-184

Stange EF, Alavi M, Schneider A, Ditschuneit $H$, Poley JR (1981) Influence of dietary cholesterol, saturated and unsaturated lipid on 3hydroxy-3-methylglutaryl $\mathrm{CoA}$ reductase activity in rabbit intestine and liver. $J$ Lipid Res 22, 47-56

Stange EF, Suckling KE, Dietschy JM (1983) Synthesis and coenzyme A-dependent esterification of cholesterol in rat intestinal epithelium. J Biol Chem 258, 12868-12875

Stange EF, Preclik G, Schneider A, Reimann F (1988) The role of enterocyte cholesterol metabolism in intestinal cell growth and differentiation. Scand J Gastroenterol 23 (suppl 151), 79-85

Stubbs CD, Smith AD (1984) The modification of mammalian membrane polyunsaturated fatty acid composition in relation to membrane fluidity and function. Biochim Biophys Acta 779, 89-137

Taatjes DJ, Roth J (1988) Alteration in sialyltransferase and sialic acid expression accompanies cell differentiation in rat intestine. Eur J Cell Biol 46, 289-298

Thomson ABR, Keelan M, Garg ML, Clandinin MT (1989) Intestinal aspects of lipid absorption: in review. Can J Physiol Pharmacol 67, 179-191

Van Dongen JM, Visser WJ, Daems WT, Galjaard $H$ (1976) The relation between cell proliferation, differentiation and ultrastructural development in rat intestinal epithelium. Cell Tissue Res 174, 183-199 
Van Heyningen S (1983) The interaction of cholera toxin with gangliosides and the cell membrane. Curr Top Membr Transp 18, 445-471

Walker WA, Cornell R, Davenport LM, Isselbacher KJ (1972) Macromolecular absorption: mechanism of horseradish peroxidase uptake and transport in adult and neonatal rat intestine. $J$ Cell Biol 54, 195-205

Weiser MM (1973) Intestinal epithelial cell surface membrane glycoprotein synthesis. I. An indicator of cellular differentiation. $J$ Biol Chem 248, 2536-2541

Weiser MM, Walters JRF, Wilson JR (1986) Intestinal cell membranes. Int Rev Cytol 101, $1-57$

Yeagle PL (1985) Cholesterol and the cell membrane. Biochim Biophys Acta 822, 267-287

Yeagle PL (1989) Lipid regulation of cell membrane structure and function. FASEB $J 3$, 1833-1842 